- Illicit drug abuse continues to be a growing problem worldwide.

- This study reports on the oral health sensations experienced (recalled) among a young adult population in a drug rehabilitation programme.

- Illicit drug abuse produces many oral health sensations and different types of illicit drugs produce different oral sensations.

- Such information is important in understanding the underlying pathological processes that bring about drug-related oral manifestations. Moreover, it may also enable clinicians to identify drug abuse from patients' reported symptoms and thus facilitate a more comprehensive and multidisciplinary approach to the management of addiction.

\title{
Oral health sensations associated with illicit drug abuse
}

\author{
C. McGrath ${ }^{1}$ and B. Chan ${ }^{2}$
}

Objectives To investigate oral health sensations (short term oral health effects) associated with illicit drug abuse. In addition, to identify variations in oral health sensations produced by different illicit drugs.

Subject Young adults in a drug rehabilitation programme in Hong Kong, China.

Method Self-completed questionnaire about their previous pattern of drug abuse and oral health sensations experienced (recalled).

Results All (119) subjects were poly-drug abusers (abused one or more illicit drugs in the past). Amphetamine-based drugs such as methamphetamine ('speed') and methylenedioxymethamphetine ('ecstasy') were commonly abused. A wide range of oral health sensations were reported on recall of their abuse of illicit drugs; most frequently dry mouth $(95 \%, 113)$. Types of illicit drugs abused were associated with oral health sensations reported $(\mathrm{P}<$ 0.001). 'Ecstasy' abusers more frequently reported chewing $(\mathrm{P}<$ $0.001)$, grinding $(P<0.001)$, and TMJ tenderness $(P<0.001)$ compared to non-'ecstasy' abusers.

Conclusion Illicit drug abuse produces many oral health sensations. Types of drugs abused were associated with oral sensations produced. and behavioural effects that may manifest as depression, anxiety, memory loss and various neuropsychotic disorders. ${ }^{8,9}$ In some cases drug abuse can result in death by various means: malignant hyperthermia, internal bleeding, fatal overdosing and through allergic reactions. ${ }^{10,11}$ Likewise, there have been reports on the long term clinical effects of illicit drug abused on oral health,

\section{INTRODUCTION}

Illicit substance abuse is on a rising trend globally. ${ }^{1}$ Substances being abused range from the more traditional opiate types, such

${ }^{1}$ Associate Professor, ${ }^{2}$ Research Assistant, Periodontology and Public Health, Faculty of Dentistry, Prince Philip Dental Hospital, University of Hong Kong

*Dr Colman McGrath, Periodontology and Public Health, Faculty of Dentistry, Prince Philip Dental Hospital, University of Hong Kong, Hospital Road, Hong Kong.

Email:McgrathC@hkucc.hku.hk

\section{Refereed paper}

Received 28.11.03; Accepted 4.03.04

DOI: $10.1038 /$ sj.bdj.4812050

๑ British Dental Journal 2005; 198: 159-162 as diacetylmorphine - 'heroin', (with an annual prevalence of about nine million abusers) to the newer amphetamine-based drugs, which have gained increased popularity recently, with over 40 million annual abusers worldwide. ${ }^{1,2}$ Amphetaminebased drugs, notably ${ }^{3,4}$-Methylenedioxymethamphetine, MDMA - 'ecstasy' have become increasingly popular, particularly on the 'dance circuit' and at 'rave parties' and are one of the most common types of drugs taken amongst teenagers and young adults. ${ }^{3-5}$ The pattern of drug abuse varies somewhat from infrequent abuse in particular social contexts termed 'recreational' abuse to continuous chronic abuse characteristic of drug addiction. ${ }^{6}$ There is much debate as to whether 'recreational' drug abuse leads to continuous chronic abuse and this appears to be related to the type and quantity of drugs abused as well as individual characteristics. ${ }^{7}$

The long term effects of abusing drugs is the risk of developing permanent brain damage with various psychological, cognitive and behavioural effects that may manifest as depression, anxiety, memory loss and various neuropsychotic disorders. ${ }^{8,9}$ In some cases drug abuse can result in death by various means: malignant hyperthermia, internal bleeding, fatal overdosing and through allergic reactions. ${ }^{10,11}$ Likewise, there have been reports on the long term clinical effects of illicit drug abused on oral health, such as dental caries associated with 'heroin', ${ }^{12}$ oral mucosal ulcerations in 1-3-8-methyl-8-azabicyclooctane-2carboxylic acid methyl ester ('cocaine') abuse ${ }^{13}$ and, tooth wear and periodontal disease associated with 'ecstasy.' ${ }^{14,15}$

The sensations or short term effects associated with drug abuse in relation to general health are well recognised and include exhaustion, nausea, hallucinations, chills, sweating, increase in body temperature, tremors, muscle cramping, blurred vision and anxiolysis. ${ }^{3,6}$ However, little has been reported on the oral sensations associated with drug abuse despite the acknowledgement of oral manifestation. ${ }^{12-17}$

Studying the oral sensation of illicit drugs is important on many fronts: it may provide information on the underlying pathological processes and thus help to explain the clinical features observed. It may also enable clinicians to identify such drug abuse from patients' reported symptoms and thus facilitate a more comprehensive and multidisciplinary approach to the management of addiction. Moreover, in the fight against illicit drug use, a better understanding of the effects of substance abuse can provide 
the public with greater information in order to make a more informed decision about their use.

\section{AIM}

The aims of this study were to report on oral sensations experienced by abusers of illicit drugs. In addition, to explore differences in oral sensation experienced in relation to the types of drug abused, namely abuse of MDMA -'ecstasy' compared to other drugs.

\section{METHODS}

\section{Sample}

Identifying drug abusers in the population can be difficult with co-operation and compliance being additional problems. This was overcome by recruiting subjects from drug rehabilitation programmes. One hundred and nineteen previous drug abusers volunteered to participate in the study. Ethical approval from the local research and ethics committee was obtained, as well as informed consent from study participants.

\section{Data collection}

A questionnaire was developed to assess (a) previous drug abuse: types of drugs abused, patterns of drug abuse and period of drug abuse, (b) self-reported oral health experiences during periods of drug abuse. Items for the questionnaire were chosen following a review of the literature on oral health and substance abuse and an inspection of recent review papers on the immediate, short term and long term systemic effects of drug use. The questionnaire was piloted among a small group of known substance abusers. Participants in the pilot study were encouraged to express their views on oral health experiences that they had after abusing illicit drugs to ensure content validity of the questionnaire. Final revisions were made to the questionnaire regarding the order of questions following the pilot study. The questionnaire was self-completed by study participants because of the sensitive nature of the questions and to ensure anonymity.

\section{Data analysis}

Frequency tables were produced to determine the profile of the group, pattern of drug abuse and oral health sensations experienced during periods of drug abuse. Variations in oral health sensations experienced associated with types of illicit drug taken was explored employing Chi-square statistics.

\section{RESULTS}

\section{Profile of the group and patterns of drug abuse}

The participants were 112 men and 7 women aged between 15 to 25 years with a mean and median age of 20 years and standard deviation of 2.52 years. The reported starting age of drug abuse in the sample ranged from 9 to 22 years, with a mean age of starting drug abuse at 15 years (SD 2.13), median age of 15 years (iqr 14, 16). Frequency of drug abuse varied from more often than once a week $(82 \%, 97)$, once a week $(10 \%, 12)$, less than once a week but more than once a month $(5 \%, 6)$ to about once a month $(3 \%, 4)$.

All were poly-drug users, abusing one or more types of illicit drugs in the past. Eighty per cent (95) claimed to have taken methamphetamine - 'speed', another amphetamine based drug. Fifty-eight per cent (69) claimed to have taken 'ecstasy', and ketamine hydrochloride - 'ketamine' was also commonly abused $(55 \%, 65)$. 'Heroin' was abused by almost half of the sample population $(48 \%$, 57). Figure 1 illustrates the profile of drugs abused in the past by the study group.

There was an association between previous abuse of "ecstasy" and abuse of other types of drugs (Table 1). Abusers of 'ecstasy' more frequently claimed they had abused other amphetaminebased drugs such as 'speed', $P=0.001$ and methampetamine

\begin{tabular}{lccc}
\multicolumn{4}{l}{ Table 1 Association between 'ecstasy' abuse and other drugs abused } \\
\hline & 'Ecstasy' users & Non-'ecstasy' users & P value \\
\hline Speed & $62(89.9 \%)$ & $33(66.0 \%)$ & 0.001 \\
Ketamine & $59(85.5 \%)$ & $6(12 \%)$ & $<0.001$ \\
Barbies & $28(40.6 \%)$ & $8(16.0 \%)$ & 0.004 \\
Heroin & $25(36.2 \%)$ & $32(64.0 \%)$ & 0.003 \\
Ice & $19(27.5 \%)$ & $4(8.0 \%)$ & 0.008 \\
Cough mixture & $19(27.5 \%)$ & $23(46.0 \%)$ & 0.037
\end{tabular}

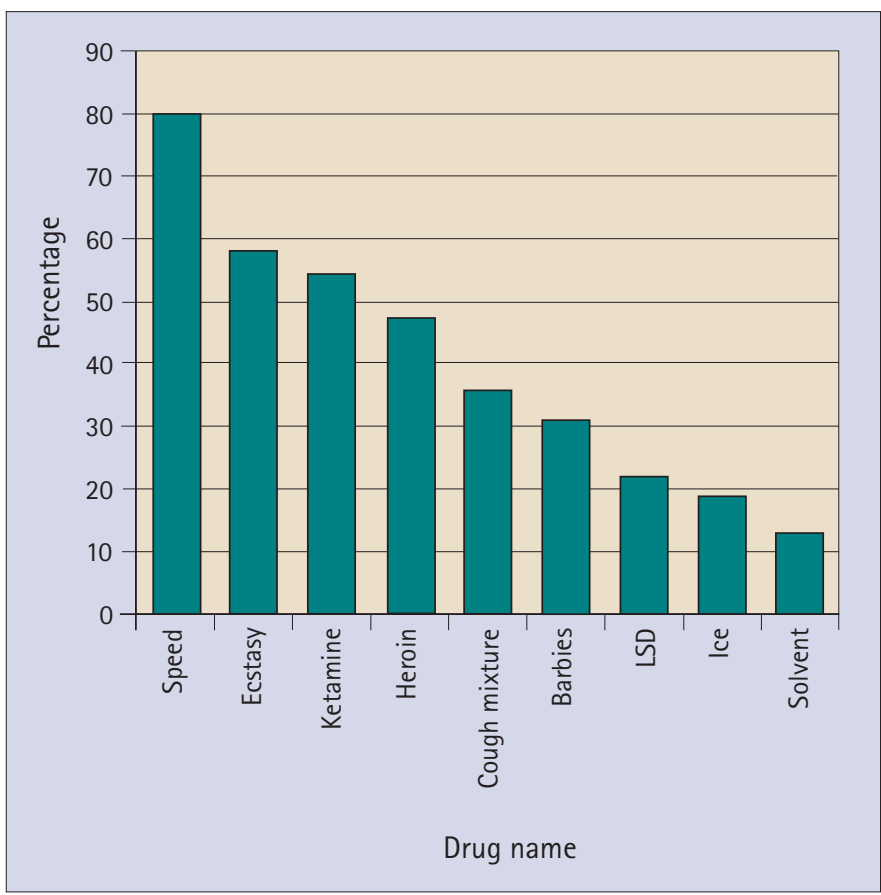

Fig 1 Reported past abuse of illicit drugs by the study sample

hydrochloride - 'ice', $P=0.008$. In addition, abusers of 'ecstasy' more frequently reported that had also abused 'ketamine', $P<$ 0.001 and barbiturates - 'barbies', $P=0.004$. However, 'ecstasy' abusers were less likely to have used 'heroin', $P=0.003$ or dextromethorphan - 'cough mixtures', $P=0.037$.

\section{Oral health experiences associated with drug use}

After the taking of the illicit drugs most recalled experiencing a wide range of oral health sensations (Fig. 2). Almost all recalled 'dryness of their mouth' $(95 \%, 113)$ and three quarters of them reported that they had 'felt like chewing something' (75\%, 89) after abusing drugs. Over half noticed that they had a habit of 'grinding or clenching their teeth together' $(52 \%, 62)$ and felt 'pain or tenderness in jaw muscle or jaw joint' $(56 \%, 66)$ after taking drugs. Over a third recalled felling some sort of 'numbness' in their mouth $(40 \%, 47)$, felt their 'teeth sensitive' $(37 \%$, 44 ) and had a habit of 'biting their cheeks, tongue or lips' (39\%, 46). Over a quarter felt their 'joints clicked or popped when eating or opening their mouth joint' $(29 \%, 35)$ and reported some 'difficulty in opening their mouth fully' $(28 \%, 35)$ after abusing drugs.

\section{Abuse of 'ecstasy' and oral health sensations}

Previous abusers of 'ecstasy' claimed they experienced certain oral health sensations more frequently compared to those who had never abused 'ecstasy'. Eighty-seven per cent (60) of 'ecstasy' abusers claimed they always felt like 'chewing something' after abusing drugs compared to 58\% (29) of those who had never taken 'ecstasy', $P<0.001$. In addition, 70\% (48) of those who abused 'ecstasy' noticed that they had a habit of 'grinding 
Table 2 Association between 'ecstasy' abuse and oral health sensations

\begin{tabular}{|c|c|c|c|}
\hline & 'Ecstasy' & Non-'ecstasy' & Pvalue \\
\hline Dryness of mouth & 68 (99\%) & 45 (90\%) & 0.035 \\
\hline $\begin{array}{l}\text { Felt like chewing } \\
\text { something }\end{array}$ & 60 (87\%) & $29(58 \%)$ & $<0.001$ \\
\hline $\begin{array}{l}\text { Grind or clench teeth } \\
\text { together }\end{array}$ & $48(70 \%)$ & $14(28 \%)$ & $<0.001$ \\
\hline $\begin{array}{l}\text { Pain or tenderness in jaw } \\
\text { muscle or jaw joint }\end{array}$ & $48(70 \%)$ & $18(36 \%)$ & $<0.001$ \\
\hline $\begin{array}{l}\text { Cheeks, tongue or lips } \\
\text { biting }\end{array}$ & $31(45 \%)$ & $15(30 \%)$ & 0.099 \\
\hline Numbness in mouth & 31 (45\%) & $16(32 \%)$ & 0.154 \\
\hline Sensitive teeth & 27 (39\%) & 17 (34\%) & 0.567 \\
\hline $\begin{array}{l}\text { Difficulty in opening } \\
\text { mouth fully }\end{array}$ & $23(33 \%)$ & $10(20 \%)$ & 0.109 \\
\hline $\begin{array}{l}\text { Joint clicks or pops when } \\
\text { eating or opening mouth }\end{array}$ & 20 (29\%) & $15(30 \%)$ & 0.905 \\
\hline
\end{tabular}

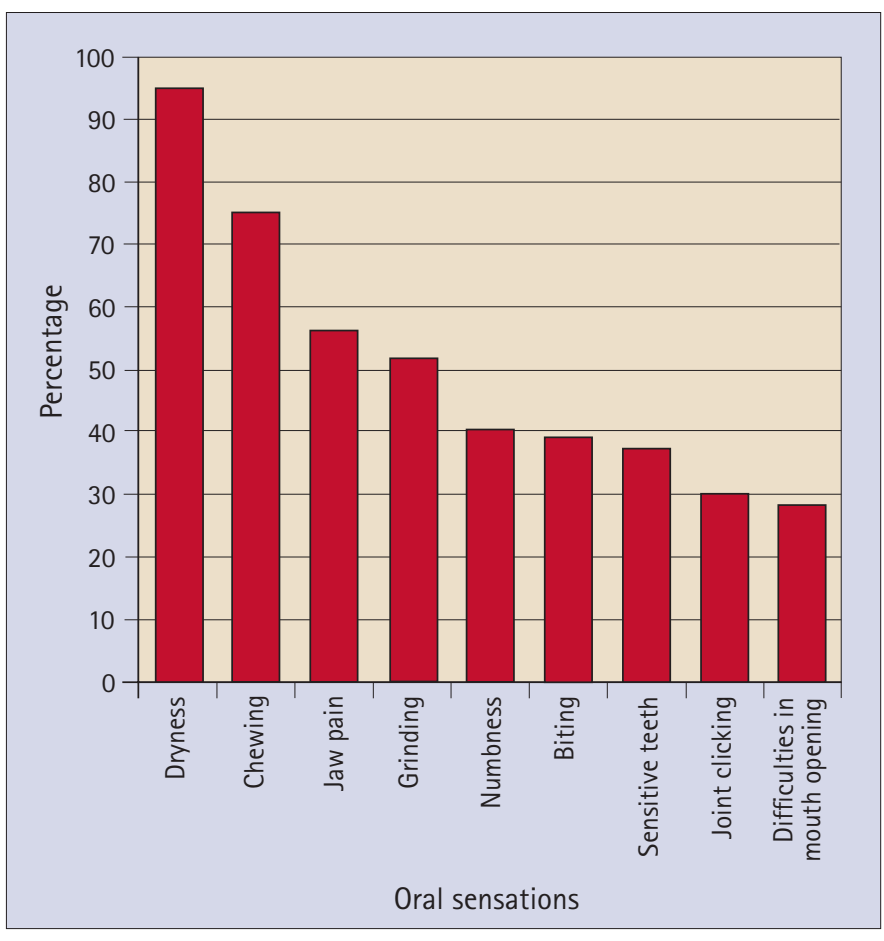

Fig 2 Oral health sensations reported relating to drug abuse experiences

or clenching their teeth together' after taking drugs compared to 28\% (14) of those who never abused 'ecstasy', $P<0.001$. Also, $70 \%$ (48) of those who abused 'ecstasy' claimed they felt 'pain or tenderness in their jaw muscle or jaw joints' compared to $36 \%$ (18) non 'ecstasy' abusers, $P<0.001$. Almost all 'ecstasy' abusers $(99 \%, 68)$ reported 'dryness of their mouth' after taking drugs compared to $90 \%$ (45) of non-'ecstasy' abusers, $P=0.035$. Variations in reported oral health sensations experienced are tabulated in Table 2.

\section{DISCUSSION}

The effects of illicit drug abuse on oral health is rarely reported probably due to aforementioned difficulties in recruiting appropriate subjects which may be overcome by focusing on those who are currently in drug rehabilitation programs as other studies have done. ${ }^{18-20}$ This method allowed obvious identification of past illicit drug abusers without the problem of stigma. This "captive' population also ensured cooperation and a high response rate that may also be a useful approach to studying other aspects of oral health relating to illicit drug abuse.
The sample in this study represents a young and predominantly male population which reflects the demographic of those in drug rehabilitation programmes. ${ }^{18-20}$ The fact that on average the participants began abusing drugs at 15 years of age confirms that illicit drug abuse is a problem which begins in teenage years. ${ }^{1,2}$ All subjects were poly-drugs abusers, hence it was not possible to study the effect of an individual illicit drug in a 'cause and effect' scenario; this is a frequently problem observed in addiction research. ${ }^{21}$ It is perhaps not surprising to find that 'ecstasy' abuse was associated with abuse of other amphetamine based drugs such as 'speed', 'ice' as well as 'ketamine' and 'barbies'. These groups of drugs are favoured by young people in raves and are sometimes referred to as 'designer drugs." ${ }^{2}$ This group of 'designer drugs' abusers seem to have a drug use profile different from those who abused the more traditional type of drugs such as 'heroin' and 'cough mixtures'.

Subjects reported that they experienced a wide range of oral health sensations after taking drugs. Almost all felt 'dryness in their mouth' (95\%) after abusing drugs. The pharmacological effects of illicit drugs, in particular amphetamine based drugs, are thought to contribute to clinically observed xerosotomia. 23,24 About a third noticed 'numbness' in their mouth after abusing drugs and this in part may reflect the analgesic properties of drug such as 'heroin', and the disassociate state produced by 'ketamine.' 25

Reported oral health sensations recalled from drug experiences were associated with types of drugs abused. Notably, 'ecstasy' abusers more frequently reported that they had always 'felt like chewing something', noticed that they had a habit to 'grind or clench teeth together' and felt 'pain or tenderness in jaw muscles or joints' compared to non-'ecstasy' abusers. This would support concerns about tooth wear as a results of abusing 'ecstasy' which have increasingly emerged in the literature. ${ }^{26,27}$ Interestingly too, abusers of ecstasy more frequently recalled sensations associated with over activity of the tempromandibular joints ('pain or tenderness in jaws', 'felt like chewing'), again probably due to the stimulant effects of the amphetamine based drug 'ecstasy' that cause an increase in muscle activity. Anecdotal concerns have been raised about the effects of 'ecstasy' abuse on tempromandibular joint dysfunction. ${ }^{14,17,26-27}$

\section{CONCLUSION}

Illicit drug abuse produces a wide range of oral health sensations. Mouth 'dryness' is a common reported short term oral health effect of drug abuse, among others. Type of drug abuse is associated with the oral health sensations produced, as evident in the difference in recalled oral health sensations among 'ecstasy' and 'non-ecstasy' abusers.

The authors would like to thank the many people who assisted in making this study possible particularly Drs Kenneth Chung, Janet Hung, Baljit Kaur, S.N. Lam, Elvis Ley, Donald Li, Tandy Wong and Freda So. In addition, we are grateful to the following drug rehabilitation centres in Hong Kong: Caritas Wong Yiu Nam Centre in Sai Kung, The Christian New Being Fellowship in Sai Kung, Christian Zheng Sheng Association in Lantau, Wu Oi Christian Centre in Lantau and those in the drug rehabilitation who gave so generously of their time and shared with us their experiences.

1. United Nations Office for Drug Control and Crime Prevention. Global illicit drug trends 2002

2. United Nations Office on Drugs and Crime. World Drug Report 2000

3. Yacoubian G S Jr, Boyle C, Harding C A, Loftus E A. It's a rave new world: estimating the prevalence and perceived harm of ecstasy and other drug use among club rave attendees. J Drug Educ 2003; 33: 187-196.

4. Weir E. Raves: a review of the culture, the drugs and the prevention of harm. Can Med Assoc J 2000; 162: 1843-1848.

5. Koesters S C, Rogers P D, Rajasingham C R. MDMA ('ecstasy') and other 'club drugs' The new epidemic. Pediatr Clin North Am 2002; 49: 415-433.

6. Solowij N, Hall W, Lee N. Recreational MDMA use in Sydney: a profile of 'ecstacy' users and their experiences with the drug. Br J Addict 1992; 87: 1161-1172.

7. Monteiro M G. A World Health Organization perspective on alcohol and illicit drug use and health. Eur Addic Res 2001; 7: 98-103. 
8. Vollenweider F X, Liechti M E, Gamma A, Greer G, Geyer M. Acute psychological and neurophysiological effects of MDMA in humans. J Psychoactive Drugs 2002; 34: 171-184.

9. Parrott A C, Sisk E, Turner J J. Psychobiological problems in heavy 'ecstasy' (MDMA) polydrug users. Drug Alcohol Depend 2000; 60: 105-110.

10. Kraner J C, McCoy D J, Evans M A, Evans L E, Sweeney B J. Fatalities caused by the MDMA-related drug paramethoxyamphetamine (PMA). J Anal Toxicol 2001; 25: 45-48.

11. Murray J B. Ecstasy is a dangerous drug. Psychol Rep 2001; 88: 895-902.

12. Rosenstein, D. I. Effect of long-term addiction to heroin on oral tissues. J Public Health Dent 1975; 35: 118-122.

13. Quart A M, Small C B, Klein R S. The cocaine connection. Users imperil their gingiva. J Am Dent Assoc 1991; 122: 85-87.

14. Milosevic A, Agrawal N, Redfearn P, Mair L. The occurrence of toothwear in users of Ecstasy (3,4-methylenedioxymethamphetamine). Community Dent Oral Epidemiol 1999; 27: 283-287.

15. Brazier W J, Dhariwal D K. Ecstasy related periodontitis and mucosal ulceration - a case report. Br Dent J 2003; 194: 197-199.

16. Pallasch T J, Joseph C E. Oral manifestations of drug abuse. J Psychoactive Drug 1987: 19:375-377.

17. Duxbury A J. Ecstasy - dental implications. Br Dent J; 175: 38.
18. Cheung Y W, Ch'ien J M. Previous participation in outpatient methadone program and residential treatment outcome: a research note from Hong Kong. Subst Use Misuse 1999; 34: 103-118.

19. Tang C S, Wong C S. Marijuana and heroin use in Hong Kong Adolescents. Subst Use Misuse 1996; 31: 115-125

20. Lo Y C, Lee $S$ S, Hollinrake J B. Practice of drug abuse among inmates of a drug rehabilitation centre in Hong Kong. Public Health 1995; 109: 201-205.

21. Darke $S$, Hall W. Levels and correlates of polydrug use among heroin users and regular amphetamine users. Drug Alcohol Depend. 1995; 39: 231-235.

22. Buchanan J F Brown C R. 'Designer drugs'. A problem in clinical toxicology. Med Toxicol Adverse Drug Exp 1988; 3: 1-17.

23. Cole J C, Sumnall H R. Altered states: the clinical effects of ecstasy. Pharmacol Ther 2003; 98: 35-58.

24. Peroutka S J, Newman H, Harris $H$. Subjective effects of 3,4 methylenedioxy methamphetamine in recreational users. Neuropsychopharmacology 1988; 1: 273-277.

25. Curran $\mathrm{H} \mathrm{V}$, Morgan $\mathrm{C}$. Cognitive, dissociative and psychotogenic effects of ketamine in recreational users on the night of drug use and 3 days later. Addiction 2000; 95: 575-590.

26. Murray M 0, Wilson N H. Ecstasy related tooth wear. Br Dent J 1998; 185: 264.

27. Redfearn P J, Agrawal N, Mair L H. An association between the regular use of 3,4 methylenedioxy-methamphetamine (ecstasy) and excessive wear of the teeth. Addiction 1998; 93: 745-748. 